\title{
Safety Culture and Collective Commitment in Organizational Context
}

\author{
Jarno Einolander $^{1}$, Jussi Kantola ${ }^{1,2}$, Hannu Vanharanta ${ }^{1,2}$, \\ Evangelos Markopoulos ${ }^{1}$ \\ ${ }^{1}$ University of Vaasa, Wolffintie 34, 65200, Vaasa, Finland \\ ${ }^{2}$ Poznan University of Technology, Faculty of Engineering Management, Poznan, Poland \\ jarno.einolander@student.uwasa.fi, jussi.kantola@uwasa.fi, hannu@vanharanta.fi, \\ epm@empross.com
}

\begin{abstract}
In nuclear power plants and process industry safety is the number one priority over profitability and productivity. In such high-risk environments where individuals work independently their decisions can lead to dangerous situations to coworkers, organizations or even to society. In many cases, a loose commitment to occupational role causes individual to perceive safety culture as something too much detailed which makes them to lose focus on what is important regarding the safety culture. In our view, this is a problem for collective safety culture to raise to a higher level. To understand organizations collective safety culture and safety consciousness it is important to analyze employees individually to see what are their internal feelings, understanding and aims. This paper presents a joint analysis of organization's safety culture and commitment towards their organization by utilizing also Company Democracy Model (CDM).
\end{abstract}

Keywords: Safety Culture $\cdot$ Commitment $\cdot$ Organization $\cdot$ Ontology $\cdot$ Evaluation $\cdot$ Self-assessment $\cdot$ Company democracy $\cdot$ Model

\section{Introduction}

In nuclear power plants and process industry safety is the number one priority over profitability, productivity and performance. In such high-risk environments where individuals work independently their decisions can lead to dangerous situations to coworkers, organization or even to society. In these kinds of organizations employees' safety consciousness, collective safety culture and their commitment to the organization and occupational role becomes extremely important.

A strong safety culture and the employees' organizational commitment are tightly linked together and complement each other. A safety culture is an extensive, organization-wide approach to safety management and is the end result of joint individual and group efforts toward values, attitudes, goals and proficiency of an organization's health and safety program [1].

The term Safety Culture is composed from the words 'Safety' and 'Culture'. The key word in this term is the Culture which is applied in Safety. Without a culture safety 
efforts, projects, initiatives and activities would be static, predictable, finite and nondeterministic.

When a person is committed to the company and its values, he also commits to its safety values and overall safety culture is developing. On the other hand, if the company has a strong safety culture, it also reflects to the commitment of the employees. Organizational commitment, therefore, provides a direct or indirect effects of various features affecting safety, such as people's levels of motivation [2].

Organizations with a safety culture show a deep concern for employee wellbeing which will lead to higher organizational commitment. According to Cooper [2] organizations with strong, clear cultures are associated with higher levels of employee commitment. A strong safety culture typically leads to organization having few at-risk behaviors, consequently they also experience low accident rates, low turn-over, low absenteeism, and high productivity [3].

In organizations with strong safety culture, everyone feels responsible for safety issues and tries to pursue them every day. Similarly, as employees with strong affective organizational commitment show "willingness to go beyond their immediate job requirements" for the sake of the organization, employees in organization with strong safety culture go beyond "the call of duty" to identify unsafe conditions and behaviors, and intervene to correct them [3]. Cooper [2] defines commitment to safety as 'an individual's identification with and involvement in safety activities', characterized by a strong acceptance of and belief in the organization's safety goals and a willingness to exert effort to improve safety in the workplace. This definition follows Porter et al. [4] definition of organizational commitment. According to their definition organizational commitment refers to "the relative strength of an individual's identification with and involvement in a particular organization", and also Rusbult and Farrell's [5] definition of organizational commitment as the willingness to deploy extra effort, the desire to remain, and the acceptance of the goals and values of the organization.

Consequently, these two aspects of working life i.e. safety culture and commitment are very well connected to each other in the development of the company's profitability and competitiveness as highly-committed employees are doing their best to help the company to be successful, and when a person is safety conscious and committed to the development and improvement of safety less costly accidents and at-risk behaviors are likely to happen, which in turn will boost the company's profitability and performance.

A good safety culture can also contribute to competitiveness in many other ways. Cooper [2] gives example that positive safety culture is used to rate contractors in tendering processes and therefore can make the difference between winning or losing a contract. Also, strong safety culture can affect people's way of thinking and lead to the development of safety features for some products which are then used as marketing devices to relay marketing messages to prospective customers; and it also positively impacts on employees' commitment and loyalty to the organization, resulting in greater job satisfaction, productivity and reduced absenteeism [2].

It must be emphasized that the development of a comprehensive "safety culture" at all levels of an organization takes time, and it requires visible and consistent leadership from senior management [6]. It is frequently a multi-year continuous process to integrate safety as a value of the organization and to an integral part of daily operations [3]. However, Parker, Lawrie and Hudson [7] point out that safety culture can vary within the organization based on the size and complexity of modern organizations. 
Because low commitment and low safety culture can create very difficult problems for organization it is very important for management and leadership to understand these complex concepts. To understand organizations collective degree of safety culture and the degree of commitment of the employees it is important to analyze employees individually to see what are their internal feelings, understanding and aims.

In this paper a multi-stage assessment process of these two important organizational characteristics that can contribute to organization's competitiveness; safety culture and organizational commitment is presented. This joint analysis is using newly developed Company Democracy Model (CDM) by Markopoulos and Vanharanta [8] and self-assessment based Evolute-methodology [9]. The Company Democracy Model considers the people to represent the most significant and valuable resources and assets that any organization has and supports high levels of individual commitment and motivation within the organization in the form of cooperation and inclusiveness regarding the decisions, plans and actions of the organization.

\section{Hybrid Ontology Methodology}

There is wide variety among organizations and people in their understanding of what "safety culture" and "organizational commitment" is and how to act to influence them in a positive way. It is also true that many individuals working in the field of safety do not know what a safety culture really is [2] even though they are talking about it. This is also without a doubt true for many managers who do not completely understand and realize what organizational commitment means and is comprised of and how to affect its development.

To understand, represent and evaluate these concepts we use ontologies. An ontology is an explicit specification of the conceptualization of a domain [10]. Ontologies define the common words and concepts (meanings) that describe and represent an area of knowledge [11]. Therefore, ontologies can explicitly define the meaning of concepts related both to safety culture and organizational commitment. By clarifying the conceptual structures of the concepts to all stakeholders, decisions are based on the proper and relevant information. This hybrid ontology-based approach aids understanding and managing the whole clearer than previous methods. Also, the changes become transparent and easy to visualize [12]

We have created two separate ontologies to evaluate these two concepts. In the Safety Culture model, there are 17 features and 51 statements, measuring different features of safety culture [13]. The statements specify an aspect of one or more features. According to Cooper's model, safety culture is an entity formed through externally observable and internally psychological factors, as well as the interaction between work, organization and people. According to the model, safety culture may be analyzed by examining three sub-groups: the management system of safety, safety atmosphere / climate and attitudes as well as behavior [14].

The Organizational Commitment/Engagement model, contains 59 features which are assessed with 237 statements. These features are categorized under relevant constructs, such as work motivation, job satisfaction, person-organization fit, perceptions of organizational support, and turnover intentions [15]. All the identified categories are grouped 
under the three main dimensions of organizational commitment—affective, continuance, and normative (cf. [16]).

By using statements employees evaluate themselves in current time and they also evaluate the level they wish or target for future. For example, they evaluate themselves regarding how engaged or motivated they are in the different aspects of their work and how committed they are to their organization [15]. The evaluation is made using the Internet-based Evolute assessment system [17, 18], in which the respondent compares the statement to linguistic labels on a continuous scale, meaning that there is a nonnumerical scale for answering each statement. From the values of statements, with fuzzy logic deduction, each competence is given a single value. The difference of target and current states can be considered as the creative tension or proactive vision of the statement [19]. The bigger the gap between the current and future state, the higher the proactive vision for that feature, and the greater the potential to improve. According to Senge [20], the creative tension is the energy that can move an individual from the place of current reality towards the reality of his own vision.

We use the proactive vision as the proof of motivation and aspiration. For example, if there is big proactive vision for some feature of safety culture, then people are motivated to improve that competence or if there is a big creative tension in some feature of commitment then the employees wish to develop this aspect of human resource environment further. Therefore, it is also wise, from organization's point of view, to arrange education or possibilities to improve those characters as it is organizations aim to guide and support employees' personal growth, development, and personal vision, in order to improve their core competencies according to the competitive pressures of the business world [21].

\section{$3 \quad$ Management and Leadership Patterns and Process}

\subsection{Process for Occupational Commitment and Safety Culture Evaluation}

Personnel consultation involves listening as well as considering the views of employees before decisions are made. One type of consulting method is the usage of selfevaluation. Self-evaluation takes place through an examination of one's own thoughts and feelings i.e., introspection. An individual doing self-evaluation can be seen as an autopoietic (self-defining) system: he or she defines himself / herself at work in the surrounding organization. A person can also evaluate an object in his or her situation, i.e. external business process by making a bottom-up extroversion of a chosen business process [22].

According to Nurminen [23] self-evaluation is an efficient method to develop oneself, manage personal growth, clarify roles, and commit to project related goals. The process of self-evaluation is a way of providing a type of formal structure to the development of organizational characteristic such as safety culture and organizational commitment. In the case of self-evaluation, the degree of its accuracy depends on whether the individuals want to evaluate themselves, and whether they do it with sufficient care to be beneficial for the purpose [24].

This research utilizes ontology-based self-evaluation [24] using Internet-based Evolute-environment. According to Barraclough and Carnino [6], self-evaluation of safety 
culture is a way to promote safety performance through the direct involvement of personnel in the critical examination and improvement of their own work. Involving personnel in the evaluation process can lead to better understanding of safety culture (in relation both to their own jobs and the organization), a broadening of knowledge of the objectives to be achieved, and the ways for achieving them.

Similarly, by asking employees to evaluate themselves regarding factors related to their commitment and engagement organization gives clear sign that they value employees' own feeling and opinions. However, this requires management to act based on the results of the evaluation. After the evaluation is conducted, employees are interested in results and how their collective opinions are utilized in decision making and put into practice. According to Ackoff [25], the values of those affected by the decision should be taken into account in a decision-making process. By consulting employees in decision-making processes, for example, by using evaluation results, makes them to feel that they are being heard, which may instill a sense of ownership over the outcomes [26]. If nothing is made accordingly, employees' engagement is likely to drop, which also makes such future project less likely to succeed because of employees increased feelings of not caring to participate such surveys.

The research methodology combines different methods to attain real situation-aware computing, to define the degree of commitment as well as the safety culture. The process focuses on covering both past and current data as well as current information in obtaining an idea of how people evaluate organizational environment regarding safety culture and sources of commitment and engagement towards their own company at present and in the future (see Figure 1). The basic principle is to try to uncover how people view their company in their minds [22]. This evaluation is done by two ontology-based self-evaluation applications described in previous chapter.

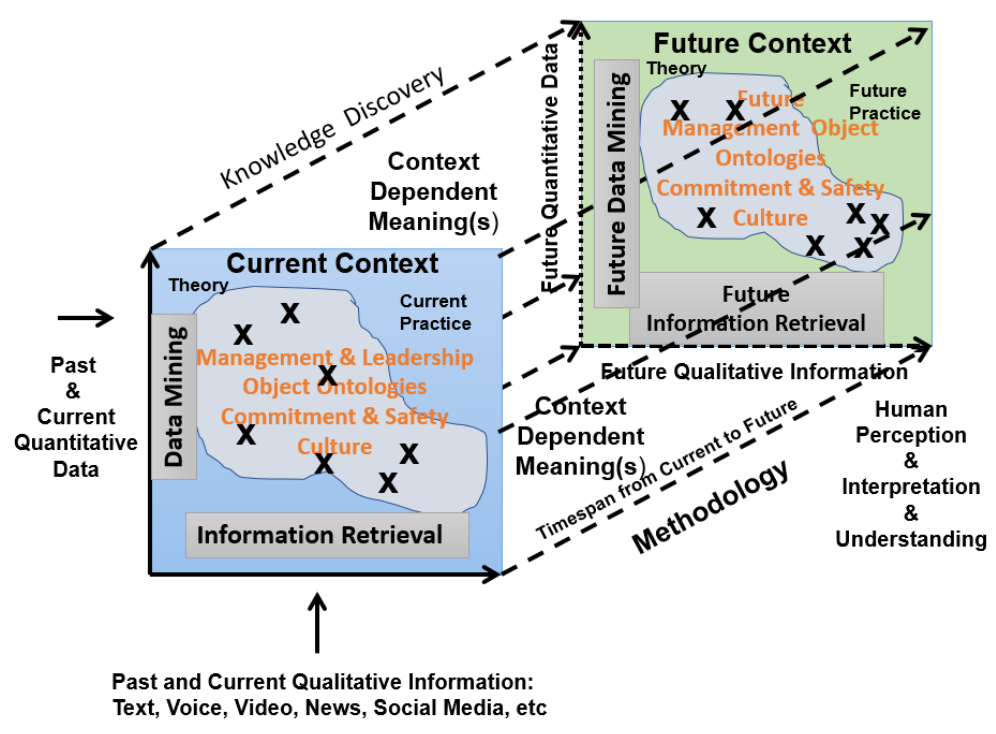

Fig. 1. Creation of Context Dependent Meanings 
In general, it is important first to understand the needs as well as the current state of the organization before targeting new organizational targets and expectations. This kind of proactive vision, created with the people inside the organization, gives the people the capability to collaborate and develop state of organization in harmony with top leaders and executives. The methodology, as well as the computer applications, supports the idea of evaluating the ontology in both its current and future state. This way, it is possible to capture the creative tension described by the test subjects of the human object ontologies as well as the future proactive vision from business object ontologies [24]. Therefore, by analyzing people's behavioral patterns in their work, meetings, decisions, and other activities, very important information can be gained about their past, to justify their present and forecast their future (see Figure 1).

After the personnel evaluations are conducted the Evolute system has uncovered the overall collective picture of the company's safety culture and its employees' commitment and engagement towards the company. It leads off from the individual level towards the collective organizational level. The collective evaluations are analyzed and the priorities and creative tensions are calculated. This type of analysis follows principles of democratic company behavior making the analysis open which is important in the positive development of safety culture and commitment. According to Slater and Bennis [27] democracy is the only system that can successfully manage the changing demands of contemporary civilization in business, as well as in government.

In order for the organization to define a common language and establish a common understanding managers and leaders must know the constructs and concepts as well as the indicators thoroughly, so that they can manage and lead these fuzzy concepts in their organization and observe how changes occur through key figures. Therefore, democratic learning of these concepts is important because it allows all individuals, managers as well as other employees, to think through these concepts themselves and learn while giving important information for the organization.

The developed approach enables a comparison between desired future and current states. Also, asymmetries among respondents can be revealed, which is crucial information from a safety culture as well as commitment point of view. The assessment identifies the distance between the "as-is" and the "to-be" in the evaluated concepts. The assessment can also define the actions, priorities, effort cost and specific human recourses needed.

This is precisely the information, data and knowledge that is required for the management and leadership of these difficult concepts. We place this to the situation-aware computing area. The results of the test runs help us to create then a present situationaware synthesis of meanings (See Figure 2). 


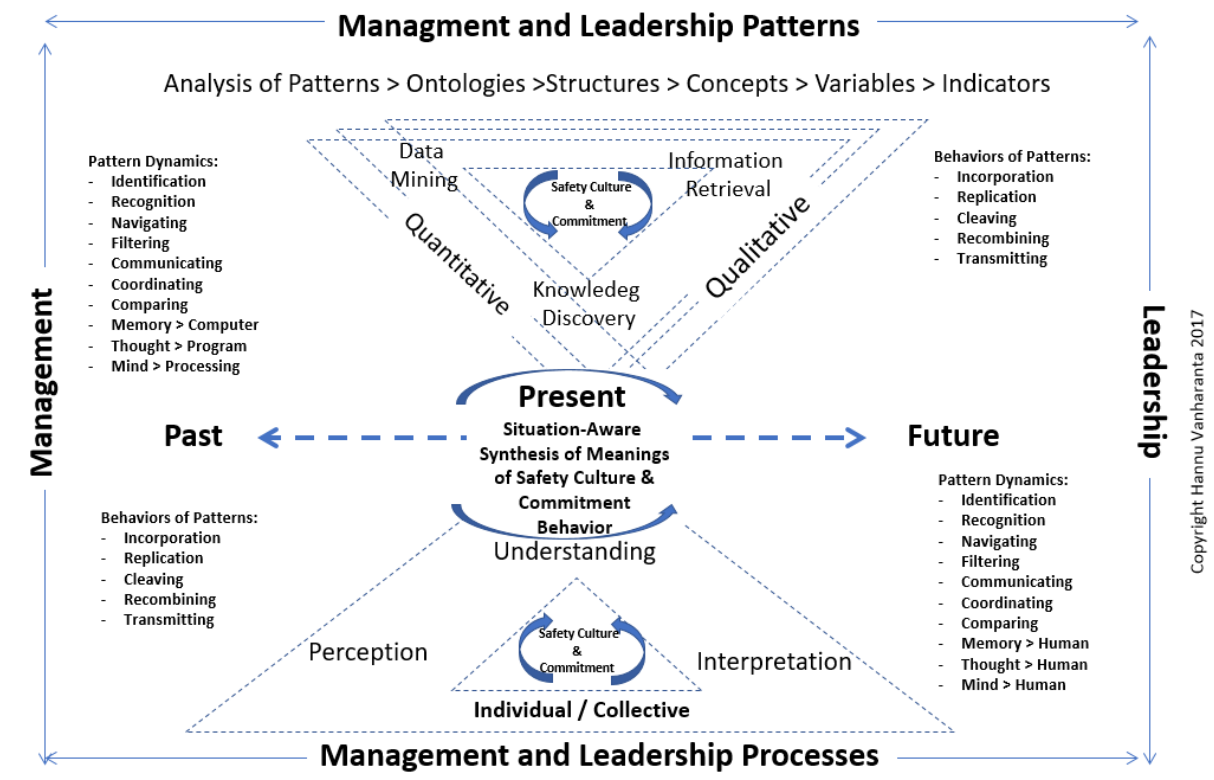

Fig. 2. Situation-Aware Computing through Ontologies

The assessment results need to be implemented and executed towards reaching the development of the organizational human resource environment and strategy and operations framework.

\subsection{Collective Understanding through Company Democracy Model}

The Company Democracy model is an applied philosophy model based on the creation of organizational culture that identifies, extracts, and utilizes knowledge in a collective way for the benefit of all [28]. The co-evolutionary spiral method in the model contributes towards the identification and achievement of the capacity, capability, competence, and maturity needed to turn information and knowledge into innovations. The spiral process, in this context, is based on the idea of the degree of democracy in organizations. The model is structured in such a way that the method reflects the Co-Evolute methodology [21] and its application in organizational democratic performance. Both organizational development methodologies (Co-Evolute and the Company Democracy Spiral Method) are aimed at the creation of an organizational knowledge-based culture $[29,30]$. Both methods utilize organizational knowledge by developing a knowledgebased organizational culture that can constantly contribute to the organization by transforming organizational tacit knowledge into explicit knowledge [10].

The Company Democracy Spiral Method levels form a pyramid structure. The pyramid shape has been chosen to point out the incremental progression of the levels and to illustrate that not all who attempt this route can reach the top without real commitment, determination, and organizational capability and maturity (Figure 3 ). 


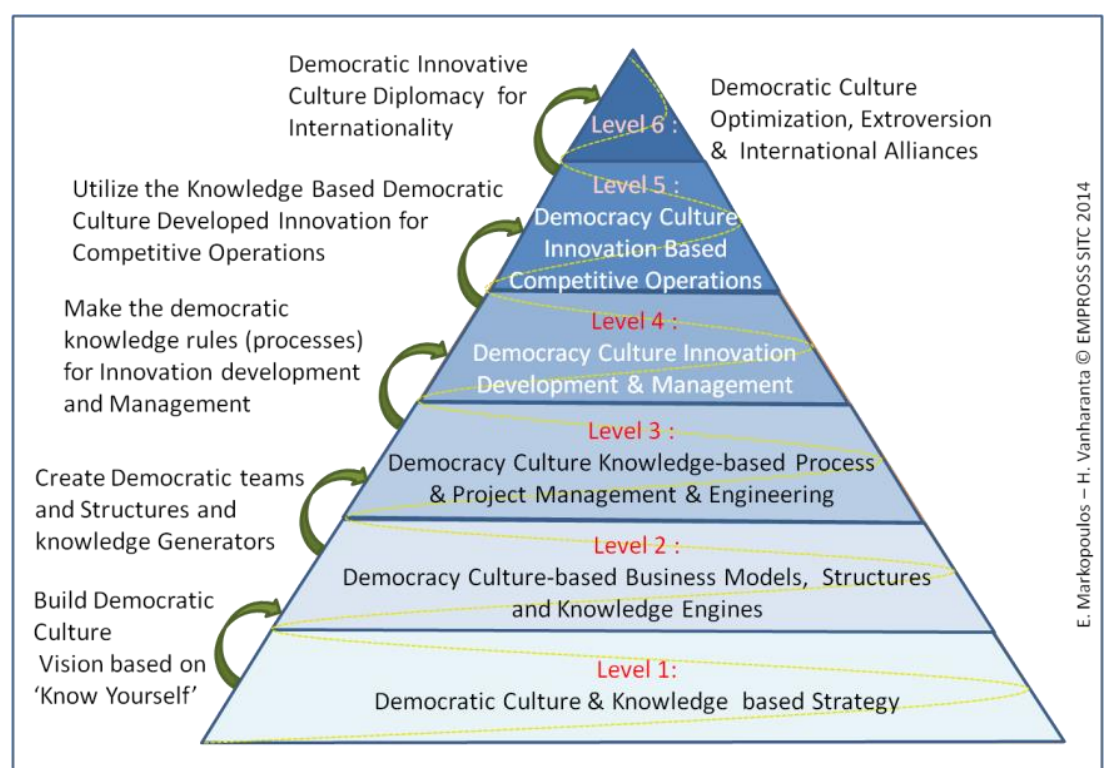

Fig. 3. The Company Democracy Model with Pyramid Stages

The Company Democracy levels provide the actions to be processed to proceed towards the identification of the degree of company democracy through a new pyramidtype representation based on the individual and collective evolution dimensions (Figure 4).

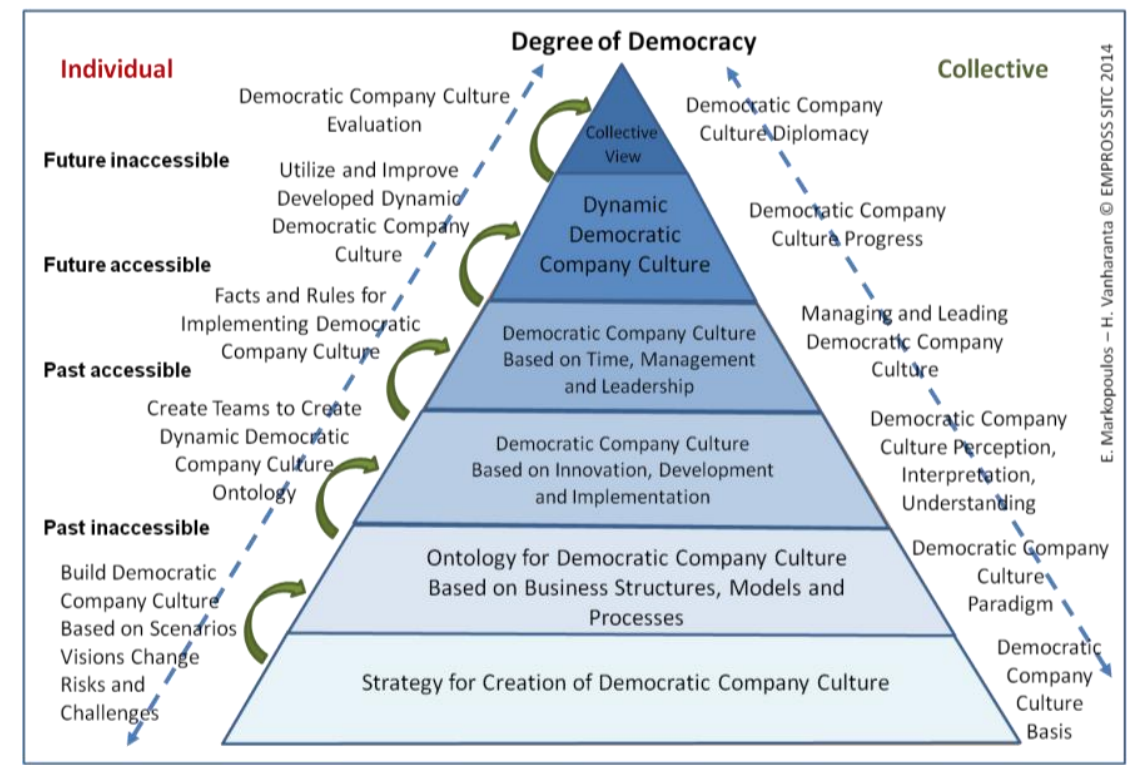

Fig. 4. Co-Evolutionary Spiral Process for Dynamic Democratic Company Culture Development 
The individual side of the pyramid can remember and see the past inaccessible part of the company democracy process, which may be accessible today and in the future. From a collective point of view, the democratic company culture basis must be firm, the created paradigm must contain all the known information, and the democratic company culture must be understood, interpreted, and perceived by each company member. Therefore, for an organization, it is important first to understand the current degree of democracy and how this degree should be improved over time, through democratically oriented changes.

As an example, by applying the model to Safety Culture, the levels can determine the evolution of the safety culture in the organization and indicative strategic goals archived in each level (Figure 5).

The first level of the Democratic Safety Culture establishes the culture via democratic processes where all people can propose, comment, suggest, think, and contribute in a dynamic and continuous safety culture framework. The second level generates the safety knowledge that derives from the democratic culture. The thirds level applies the safety knowledge in the organization via new processes, practices, projects and initiatives. The fourth level utilizes the results of the application of the safety knowledge via innovation generated from the effective application of the knowledge. The fifth level capitalizes in financial terms and in profit generation, the knowledge and the effectiveness of the safety culture. The sixth level institutionalizes the safety knowledge and exports its added value to the society, the economy and the market. The six levels are repeated over and over (via the spiral theory) as the safety knowledge targets can be expanded or rolled out in an organization.

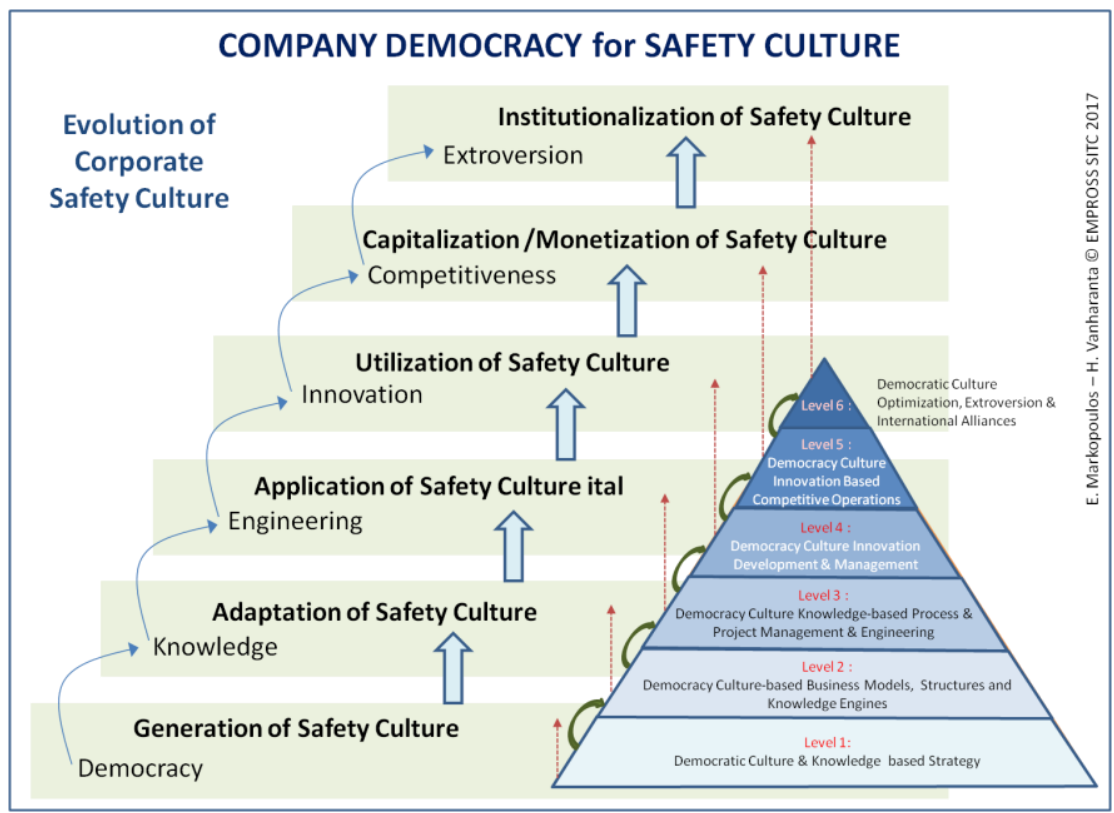

Fig. 5. Evolutionary of the Safety Culture through the Company Democracy Model 


\subsection{Application Technology Behind the Evaluation Method}

People are not good at making precise yet significant statements about a complex system's behavior [31]. This means that accurate observations cannot be made about safety culture and commitment. These concepts take place in complex social systems that involve many humans and other system parts.

Fuzziness in linguistics can be captured by creating linguistic variables that "contain" fuzzy sets $[32,33]$. Fuzzy sets represent complex systems, such as safety culture and commitment, better than crisp sets for two reasons: 1) the predicates in propositions that represent a system don't have crisp denotations; 2) explicit and implicit quantifiers are fuzzy [34]. A fuzzy set can be defined mathematically by assigning to each possible individual in the universe of discourse a value that represents its grade of membership in the fuzzy set. This grade corresponds to the degree to which that individual is similar to or compatible with the concept represented by the fuzzy set [35]. In this work, the perception of different aspects of safety culture and commitment becomes a degree of membership in fuzzy sets. Just like in real life, everything is a matter of degree. Linguistic variables bridge the gap between the numerical space and the meaning in the human mind. This means that meaning-based research and tools can be developed in numerical space.

Fuzzy logic [31] allows reasoning using fuzzy sets and fuzzy rules. A translation system represents the meaning of semantic entities, and an inferential system arrives at an answer to a question that relates to the information resident in a knowledge base [34]. The knowledge base refers to the concepts (ontology) of safety culture and commitment in this case. A fuzzy logic application resembles an expert's task to evaluate and reason based on linguistic information.

\section{Conclusions}

As seen from the research these ontologies and applications support each other and the subject discussed requires extensive learning from organizations both from the content of a safety culture and the content of the organizational commitment and engagement.

There is a strong evidence that competence-based self-evaluation applications, i.e. human- compatible systems, clearly recognize individuals' own current reality and their needs for professional and personal development. We can show the collective feeling among the respondents, how they felt right at that moment, and where they feel there is most room for improvement. Based on the individuals' current and future visions, human resource development and other action plans of the company can then be done in a much more targeted way and also the future competence paths can be simulated. The applications show clearly the priorities that the organization should put their mind into and work together to develop and improve.

The aim of the evaluations is to advance people's knowledge about the subjects and at the same time improve safety culture through commitment and vice versa in interactive manner via connections between the ontologies. By combining the top-down management view with bottom-up understanding, it is possible to control, steer and command both the financial and the human resources to the targeted objectives and goals. 
The evaluation runs must be made from time to time and by examining the result appropriate resources should be allocated to improve these and the whole organization.

\section{References}

1. Zizzo, S.: 8 steps to a strong safety culture, http://www.ishn.com/articles/91474-8-steps-toa-strong-safety-culture.

2. Cooper, D.: Improving safety culture: A practical guide. Wiley (1998).

3. Creating a Safety Culture, http://www.oshatrain.org/notes/2inotes03.html.

4. $\quad$ Porter, L.W., Steers, R.M., Mowday, R.T., Boulian, P.V.: Organizational commitment, job satisfaction, and turnover among psychiatric technicians. Journal of applied psychology. 59, 603 (1974).

5. Rusbult, C.E., Farrell, D.: A longitudinal test of the investment model: The impact on job satisfaction, job commitment, and turnover of variations in rewards, costs, alternatives, and investments. Journal of applied psychology. 68, 429-438 (1983).

6. Barraclough, I., Carnino, A.: Safety Culture. IAEA BULLETIN. 40, 2 (1998).

7. Parker, D., Lawrie, M., Hudson, P.: A framework for understanding the development of organisational safety culture. Safety science. 44, 551-562 (2006).

8. Markopoulos, E., Vanharanta, H.: The Company Democracy Model for the Development of Intellectual Human Capitalism for Shared Value. Procedia Manufacturing. 3, 603-610 (2015).

9. Kantola, J.: Ontology-based resource management. Human Factors and Ergonomics in Manufacturing \& Service Industries. 19, 515-527 (2009).

10. Gruber, T.R.: A translation approach to portable ontology specifications. Knowledge acquisition. 5, 199-220 (1993)

11. Obrst, L.: Ontologies for semantically interoperable systems. In: Proceedings of the twelfth international conference on Information and knowledge management. pp. 366-369 (2003).

12. Kantola, J., Karwowski, W., Vanharanta, H.: Managing managerial mosaic: The Evolute methodology. Electronic globalized business and sustainable development through IT management: Strategies and perspectives. 77-89 (2011).

13. Porkka, P., Mäkinen, E., Vanharanta, H.: Safety Culture Research in a Finnish Large-Scale Industrial Park. CHEMICAL ENGINEERING. 31, 361-366 (2013).

14. Porkka, P., Salo-Pihlajamäki, M., Vanharanta, H.: Proactive vision for the safety culture in a Finnish chemical plant. In: In: Karwowski, W. I\& Salvendy, G.(eds.). Proceedings of the 3rd International Conference on Applied Human Factors and Ergonomics (AHFE), 17-20 July 2010, Miami, Florida, USA (2010).

15. Einolander, J.: Organizational commitment and engagement in two finnish energy sector organizations. Human Factors and Ergonomics in Manufacturing $\backslash \&$ Service Industries. 26, 408-423 (2016).

16. Allen, N.J., Meyer, J.P.: The measurement and antecedents of affective, continuance and normative commitment to the organization. Journal of occupational psychology. 63, 1-18 (1990).

17. Kantola, J.: Ingenious management. Tampere University of Technology. Publication. 568, (2005).

18. Kantola, J., Vanharanta, H., Karwowski, W.: The evolute system: A co-evolutionary human resource development methodology. International encyclopedia of ergonomics and human factors. 2894-2900 (2005).

19. Senge, P.: The fifth discipline. Doubleday Business, New York (1990).

20. Senge, P.M., Suzuki, J.: The fifth discipline: The art and practice of the learning organization. Currency Doubleday New York (1994). 
21. Kantola, J., Vanharanta, H., Karwowski, W.: The evolute system: A co-evolutionary human resource development methodology. International Encyclopedia of Human Factors and Ergonomics. 3, 2902-2908 (2006).

22. Vanharanta, H.: Co-evolutionary design for human-compatible systems. In: In: Sinay, J. et al.(eds). CAES'2005, International Conference on Computer-Aided Ergonomics, Human Factors and Safety: Information Technology, Knowledge Management and Engineering for Enterprise Productivity and Quality of Working Life. May 25-May 28, (2005).

23. Nurminen, K.: Deltoid-The competences of nuclear power plant operators. Master of Science Thesis, Tampere University of Technology at Pori, Finland. (2003).

24. Kantola, J.: Organizational Resource Management: Theories, Methodologies, and Applications. CRC Press (2015).

25. Ackoff, R.L.: Management in small doses. Wiley (1986).

26. Robertson-Smith, G.: Employee engagement: A review of current thinking. Institute for Employment Studies (2009).

27. Slater, P., Bennis, W.G.: Democracy is inevitable. Harvard Business Review. 68, 167-176 (1990).

28. Markopoulos, E., Vanharanta, H.: Democratic Culture Paradigm for Organizational Management and Leadership Strategies-The Company Democracy Model. Advances in Human Factors and Sustainable Infrastructure. 2, 12 (2014).

29. Paajanen, P., Piirto, A., Kantola, J., Vanharanta, H.: FOLIUM-Ontology for organizational knowledge creation. In: In: Callaos et al.(eds.). WMSCI 2006, the 10th World Multi-Conference on Systemics, Cybernetics and Informatics. July 16-19, 2006, Orlando, Florida, USA. Proceedings (2006).

30. Kantola, J., Vanharanta, H., Paajanen, P., Piirto, A.: Showing asymmetries in knowledge creation and learning through proactive vision. Theoretical Issues in Ergonomics Science. 13, 570-585 (2012).

31. Zadeh, L.A.: Outline of a new approach to the analysis of complex systems and decision processes. Systems, Man and Cybernetics, IEEE Transactions on. 28-44 (1973).

32. Lin, C.-T., Lee, C.S.G.: Neural Fuzzy Systems: A Neuro-fuzzy Synergism to Intelligent Systems. Prentice-Hall, Inc., Upper Saddle River, NJ, USA (1996).

33. Zadeh, L.A.: Fuzzy sets. Information and control. 8, 338-353 (1965).

34. Zadeh, L.A.: Commonsense knowledge representation based on fuzzy logic. Computer. 16, 338-535 (1983)

35. Klir, G., Yuan, B.: Fuzzy sets and fuzzy logic. Prentice hall New Jersey (1995). 